\title{
PECS: An Evidence-Based Orientation Event Framework for Enhancing Students' Sense of Belonging
}

\author{
Rhys Cooper \\ Griffith University, Australia
}

\begin{abstract}
In 2020, staff at Griffith University, Australia used a best practice and evidence-informed orientation event framework to create the University's first series of fully online, university-wide orientation sessions. The PECS design framework was created to ensure that orientation events at Griffith focused on developing students' sense of belonging at their institution. For the first time, this framework was used as the foundation of the new "Griffith Welcome Sessions". This study uses established qualitative methods to analyse 572 student surveys about the Griffith Welcome Sessions. It finds that the use of a PECS orientation design framework improved students' orientation experience and helped them to develop a sense of connection at university. This study also establishes that the PECS-based orientation sessions remained a key driver for many students' continued sense of belonging five weeks after the sessions were delivered.
\end{abstract}

Keywords: Orientation; transition; PECS; belonging; online.

\section{Introduction}

In early 2020, the Student Transition and Mentoring (STAM) team at Griffith University responded to campus closures by redesigning the framework and structure of the University's student orientation. For the first time at Griffith, four 70-minute, university-wide, centrally delivered, and fully online "Griffith Welcome Sessions" were created and presented using Microsoft Teams and Microsoft Teams Live. The sessions were designed based on STAM's evidence-informed orientation event design framework, PECS (purpose, expectations, connections, support), initially developed as a resource for all staff organising orientation events at Griffith.

The present study aimed to understand whether the PECS-based orientation sessions, designed and delivered for the first time in July 2020, were successful in creating consistent and enjoyable orientation experiences that helped students to develop a sense of belonging at Griffith. Through analysis of two rounds of student surveys, this study seeks to answer three questions:

1. To what extent do orientation events designed using the PECS framework support the development of commencing students' sense of belonging?

2. To what extent do orientation events designed using the PECS framework support an enjoyable student experience?

3. To what extent did the effects of these orientation events on students' sense of belonging (if any), continue through the academic trimester. 


\section{Literature Review}

The PECS framework was created after an extensive survey of published research and best practice models related to university orientation, transition, and retention. As the STAM team's key directive is to maintain and improve student retention rates at Griffith, the research survey focused on how orientation and transition had been shown to positively influence higher retention rates. Through this review it was found that students' likelihood of retention, success, and wellbeing is strongly linked to their sense of belonging at an institution.

The first major study on the importance of university students' sense of belonging was Tinto's seminal book, Leaving College. Tinto outlined how students' integration into academic and social communities led to better student outcomes both in grades and retention (1993, p. 118). Tinto offered a retention framework dubbed the "Student Integration Model" which proposed that students' pre-entry and background attributes, goal commitments, institutional experiences, and integration with their institution all contributed to students' final "departure decisions" (p. 2-11). Many studies that have aimed to measure students' sense of belonging and its effects using Tinto's framework of social and academic integration, have almost unanimously supported the idea that integration —or, in more modern lexicon, "a sense of belonging"- profoundly shapes student retention and attrition rates (Beil et al., 1999). While focusing on different aspects of retention, and often a different means of measuring students' sense of belonging, studies throughout the late 1990s, 2000s, and 2010s have persistently shown the important link between retention and the successful development of students' sense of belonging.

The importance of a sense of belonging as it relates to retention in the Australian context was first outlined in Krause et al.'s (2005) study into the first-year experiences of Australian higher education students. Krause and colleagues conducted 8,981 first-year student surveys across three rounds over the course of 10 years. The team added a "set of questions on student identity and sense of belonging to a learning community" in the final round of surveys in 2004 (p. 6). The inclusion of questions about students' sense of belonging indicates that social integration had become an important new element in Australian higher education retention theory.

Krause et al.'s study was in part responsible for the development and wide implementation of Sally Kift's (2009) "transition pedagogy", which used student and staff feedback, government and university reports, as well as broad consultation with higher education design leaders to establish best practice guidelines for creating engaging and positive first year experiences among Australian university students. In this transition pedagogy, Kift outlined how the development of a strong sense of belonging among students was beneficial "not only for early engagement and retention, but also as foundational for later year learning success and a lifetime of professional practice" (p. 1). Subsequent studies of successful higher education transition strategies have supported Krause et al. and Kift's assertions, showing that the development of students' sense of belonging is the key factor for successful transition and increased likelihood of retention (Ahn, 2017; Ahn \& Davis, 2020; Chiu et al., 2016; Davis et al., 2019; Morrow \& Ackermann, 2012; O’Keeffe, 2013).

Since Krause et al. and Kift's work, there has been a growing scholarship investigating the best methods for developing a sense of belonging during students' transition into university. One of the main strategies outlined by many of these studies is the facilitation of peer-to-peer connections. In a recent article, Gijn-Grosvenor and Huisman (2020) asked students at an orientation stall to provide written answers to the question: "what would help you to feel that you belong at Macquarie University?" They received 209 responses and used NVivo software to qualitatively analyse the data. The results indicated that students saw the development of social networks, and particularly friendships, as essential to the development of "belonging".

While the study undertaken by Gijn-Grosvenor and Huisman focused on a single semester of orientation-related activities, a team at Griffith University collected and collated evaluation data over four years of a Bachelor of Education orientation program (O'Brien et al., 2012). The team used an Institutional Integration Scale developed by Pascarella and Terenzini (1980) to survey 200 first-year students before and after their involvement in the peer connections program. They found that while a significant number of students ( $\mathrm{n}=77)$ felt "worry about not belonging", they discovered that such concerns were significantly reduced at the end of the six-week orientation program — which focused on fostering peer-to-peer connections.

Many other studies, across a variety of institutions, have also found that the building of social connections between students can directly improve their sense of belonging and likelihood of retention (Ahn, 2017; Beil et al., 1999; Larmar \& Ingamells, 2010; O'Keeffe, 2013; Pittaway \& Moss, 2006; Thomas, 2013; Thongsawat et al., 2019; Tokoya, 2019). As such, the PECS 
framework promotes the design of orientation events that offer ample opportunities for students to interact, connect, and form friendships. The PECS framework also recommends that, where possible, other parts of the framework are delivered through active and problem-based learning methods.

While providing students the opportunity to connect with their peers is argued to be the best means of forming students' sense of belonging, further research also suggests that there are complementary practices that can enhance student belonging and likelihood of retention. Helping students to identify their university and post-university goals has been demonstrated to make students feel more motivated to study and at home in their university environment (Cabras \& Mondo, 2018; Hodgkinson \& Innes, 2001; Thomas, 2013; Webb \& Spiese, 2018). Studies have also shown that encouraging students to set realistic expectations about their academic workload is important in preparing them for university and, subsequently, improving their understanding of, and sense of belonging at, an institution (Dilekmen, 2007; Kuh, 1991; Singer, 2003; Tokoya, 2019). Another consistently successful method for improving students' sense of belonging and likelihood of retention at university is the provision of information about university support services and how students can access them (Brunelle-Joiner, 2000; Cohen, 2019; Collins \& Dodsworth, 2011; Larmar \& Ingamells. 2010; Miles, 2019).

The STAM team synthesised the key themes and practices identified in this research review and developed a model to promote them. The PECS framework was shared as an optional resource that orientation coordinators in Griffith's schools and faculties could use to guide the design of evidence-informed orientation events. It was strongly recommended that all elements of the PECS framework be integrated into peer-to-peer activities.

\section{Table 1}

The PECS Model as it is Promoted to School and Faculty Stakeholders

Purpose: Assist students to develop and identify goals that their degree will help them to achieve. Having a sense of purpose has been shown to improve retention rates.

Expectations: Outline the workload required of a student (i.e. 10-12 hours of work, per subject, per week), helping them to understand and plan for university expectations.

Connections: Help students to connect with one another. This supports them to make friends and develop a sense of belonging - the key factor that drives university retention and success.

Support: Provide a brief overview of the wide range of services available to students and practical processes for how to access them.

\section{PECS in Practice}

In response to campus closures in 2020, the STAM team created and delivered university-wide, fully online orientation events (Griffith Welcome Sessions) of which the design was fundamentally grounded on the PECS orientation event framework. Separate, identical sessions were delivered for each faculty at Griffith in order to connect students from the same areas, and to fit in with discipline-based orientation timetables. These sessions were presented entirely by student mentors, via Microsoft Teams Live Events, and encouraged students to engage in activities and challenges in purpose-built Microsoft Teams spaces. Microsoft Live and Teams were chosen as the delivery and activity platforms because they effectively connect students while providing session scalability - the sessions have been successfully delivered to cohorts ranging from 80 to 1,200 participants since launch.

Outside of a short introduction, overview, and outline of the purpose of the orientation session, run-through of the key course and student administration resources at Griffith (such as the Learning Management System), and a conclusion summarising the key points of the event, the Griffith Welcome Sessions were entirely activity-based. These activities offered students a platform to share things about themselves and learn about one another. The activities also encouraged students to reflect on their goals for university and beyond, discover and discuss key university services available to them, and consider the study workloads expected of them when they start university. Gift vouchers were offered to students who got most of the activity questions right, 
whose responses are voted for the most by other students, and who complete activities such as attaching a photo of themselves to their Microsoft Teams profile. Alongside the competition, students were also told about the potential benefits of taking part in the orientation activities, with the aim of providing students both intrinsic and extrinsic motivations to engage with the event and their peers. Thus, the sessions applied all features of the PECS orientation event framework with the aim of fostering students' sense of belonging.

Table 2

The PECS Model as Implemented in the Griffith Welcome Sessions

Purpose: As part of the extended "ice-breaker" activity at the start of the session-where the session presenter asked students questions, and they replied via text in their assigned Team channels - the questions "what would you like from your university experience?" and "where would you like your university experience to take you?" were asked. The presenter discussed how thinking and sharing university and post-university goals can support retention and success.

Expectations: A multiple choice question was posted on all Teams channels asking students "how many hours per course, per week, should you study and attend classes?" The presenter than asked students to think about and discuss how they could best incorporate this study time into their current routines.

Connections: An extended "ice-breaker" activity ran for the first twenty minutes of the session, in which students were asked a series of questions, each offering students the opportunity to share things about themselves. Student mentors operated within the Teams channels to promote connections and conversations and the relevant faculty "Welcome Mentor" shared their university tips and experiences. Two further peer-based activities occurred during the one-hour session about university services and workload expectations/time management. Students were also encouraged to add their photos to their Teams account and were encouraged to continue using their Teams spaces after the orientation session to connect with peers and mentors.

Support: A structured, competitive, fifteen-minute activity in which students were asked to search for and find Griffith services, share the relevant links in their Teams spaces, and discuss with their peers how the services can support students.

The Griffith Welcome Sessions offer just one model for how the PECS framework can be applied to an orientation event design, yet they provide an excellent example of how the PECS framework focuses on creating student-to-student connections with the aim of enhancing students' sense of belonging at university. As the Griffith Welcome Sessions have been wholly designed based on the PECS framework, they offer the best means of testing whether PECS is effective at fostering a sense of belonging among commencing student cohorts.

\section{Methodology and Methods}

To understand the influence of Griffith's PECS-based orientation sessions on commencing students' sense of belonging, an adapted version of Krause et al. (2005) and O'Brien et al.'s (2012) methods was used to survey Griffith's Trimester 22020 commencing student cohort over two stages. Both a quantitative and thematic analysis of this data was undertaken to determine the success of the Griffith Welcome Sessions, and therefore, the PECS framework.

As the primary aim of this study was to assess the effect of university-wide orientation sessions on new students' sense of belonging, the first survey was distributed to students as part of a voluntary activity at the end of each orientation event. This ensured that the results measured related primarily to the central orientation sessions - as opposed to faculty, school, or program orientation events. The second and final survey measured the effects of these sessions after five weeks and was distributed among students via the Microsoft Teams space used for conducting activities during the orientation sessions. Thus, this study followed O'Brien et al.'s (2012) method of surveying the same cohort twice - and therefore accepted many of the already outlined limitations of the data received from the second survey.

These surveys also used an adapted version of Bollen and Hoyle's Sense of Belonging Scale from their Perceived Cohesion Scale framework (1990). Bollen and Hoyle's questions were measured through Likert scales from 1 (strongly disagree) to 5 (strongly agree). 
The questions in Bollen and Hoyle's Sense of Belonging Scale (adapted for the Griffith context) were as follows:

\section{Ifeel a sense of belonging to Griffith.}

2. I feel that I am a member of the Griffith community.

3. I see myself as part of the Griffith community.

A Likert scale question was also included in the initial surveys and asked students: "How would you rank this orientation session?" Students had the option to rank the session from 1 (very poor) to 5 (excellent). This question was the last of the survey, after both the sense of belonging scale questions and the qualitative open answer question. This positioning was intentional and aimed to ensure that students answered the first questions broadly and without explicitly ranking their sense of connection in the context of the orientation session. This question was also carefully worded, in alignment with Fink's (2002) model of survey question formulation, to avoid leading students' answers through the use of loaded or bias wording.

In addition to the quantitative results that were surveyed using Bollen and Hoyle's (1990) Sense of Belonging Scale, the STAM team assessed — as much as is it was possible — why students felt or did not feel a sense of belonging at Griffith. To achieve this, a long-answer question modelled on Gijn-Grosvenor and Huisman's (2020) recent study was added to the survey. The Orientation Week and week five surveys asked: "Has anything helped you to feel that you belong at Griffith?" As with GijnGrosvenor and Huisman's, the wording of this question was designed in an effort not to "lead" students' responses. This data was then run through NVivo software to isolate response trends. By following Bollen and Hoyle's Sense of Belonging scale, and applying the qualitative method used by Gijn-Grosvenor and Huisman, the efficacy of the PECS-based orientation sessions was assessed using mixed methods.

\section{Results}

Of the 876 students who attended the four Griffith Welcome Sessions, 467 participants completed online surveys. To the question "how would you rank this orientation session?" (with 1 being "very poor" and 5 being "excellent") there was an average rating of 4.3 out of 5. Eighty-three percent (n. 388) of students rated the sessions as "good" or "excellent". Crucially, these scores were consistent across all sessions. This means that one of the key aims of the STAM team-to provide consistent, informative, and enjoyable sessions for all commencing students—was largely achieved.

\section{Figure 1}

Responses to Question “How Would you Rank this Orientation Session?” (\%)

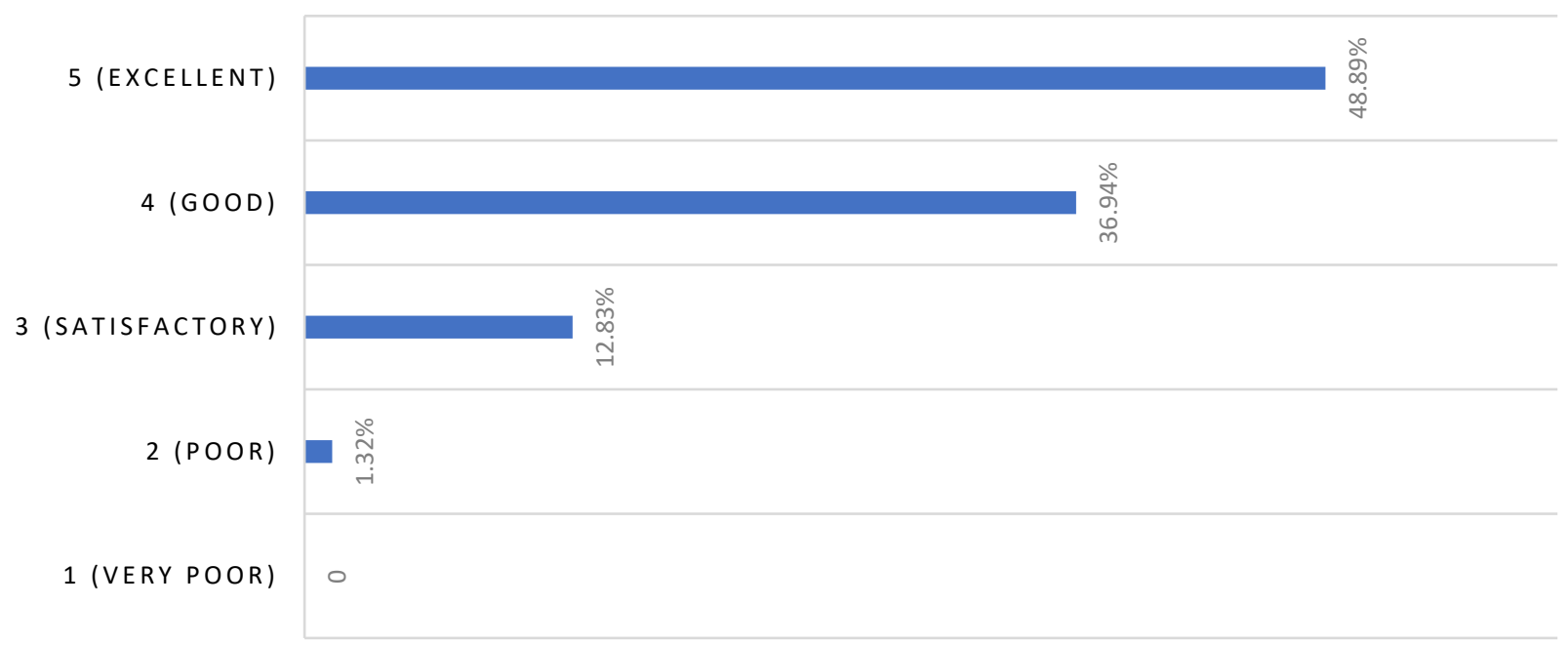




\section{Sense of Belonging}

Responses to the sense of belonging scale statements were slightly lower than the overall orientation satisfaction ratings. Students were asked to rate from 1 (strongly disagree) to 5 (strongly agree) the accuracy of the statements: "I feel a sense of belonging at Griffith", "I feel that I am a member of the Griffith community", and "I see myself as part of the Griffith community". All three markers registered the average responses to these statements as 3.7 out of 5. Further, of the 1,401 overall responses received for these three statements, 854 (61\%) indicated students' strong or moderate sense of belonging at Griffith, while $418(30 \%)$ responses indicated neither agreement nor disagreement with the sense of belonging propositions. Only 126 $(9 \%)$ responses registered disagreement to the sense of belonging statements.

The question, "has anything helped you to feel that you belong at Griffith?", was also included in the survey. The 467 responses were analysed through a word frequency query using NVivo. The most frequently used word among student answers was "orientation" ( $n=103$ ), with "helpful" (n.=64), "welcoming" (n.=34), "supported" (n.=34), "connected" ( $=28$ ), and "friends" $(\mathrm{n} .=26)$ also common in the responses. A thematic analysis of these responses, in which each response was marked in one or more of 13 categories, offered further insight to students' orientation experiences. ${ }^{1}$ Categories were created when more than one student marked a specific factor as contributing to or diminishing their sense of belonging at Griffith. Of the 498 factors provided in the responses for students' enhanced or diminished sense of belonging, the most frequently mentioned were the Griffith Welcome Sessions, which were positively referred to by students $299(60 \%)$ times. Students outlined how being brought together and interacting with their peers in the interactive sessions helped them to feel more welcome and connected at Griffith. One student responded that, "the activities held during online orientation helped me to see that there are others who share the same interests as me." Another student answered that the "orientation online games made me feel more connected to my fellow students and was very helpful in exploring services." Almost all free answer responses were positive, with just 35 (7\%) students indicating that they did not feel as though they belonged at Griffith. Sixteen of these students answered the question with either the words "no", "nil", "none", or "not really", but the remaining 19 respondents qualified their answers by referencing the disconnection caused by campus closures. One of these students wrote that "it would be better to do this in person, but that's not your fault." Another student responded that "I haven't even stepped foot on campus yet, so no not really." While only 16 students specifically identified campus closures as the reason for their not having developed a sense of belonging at Griffith, it is likely that this impediment strongly influenced many of the 113 students who disagreed with the sense of belonging statements but did not specify why in their free answer responses.

\section{Figure 2}

Likert Responses to Orientation Survey (\%)

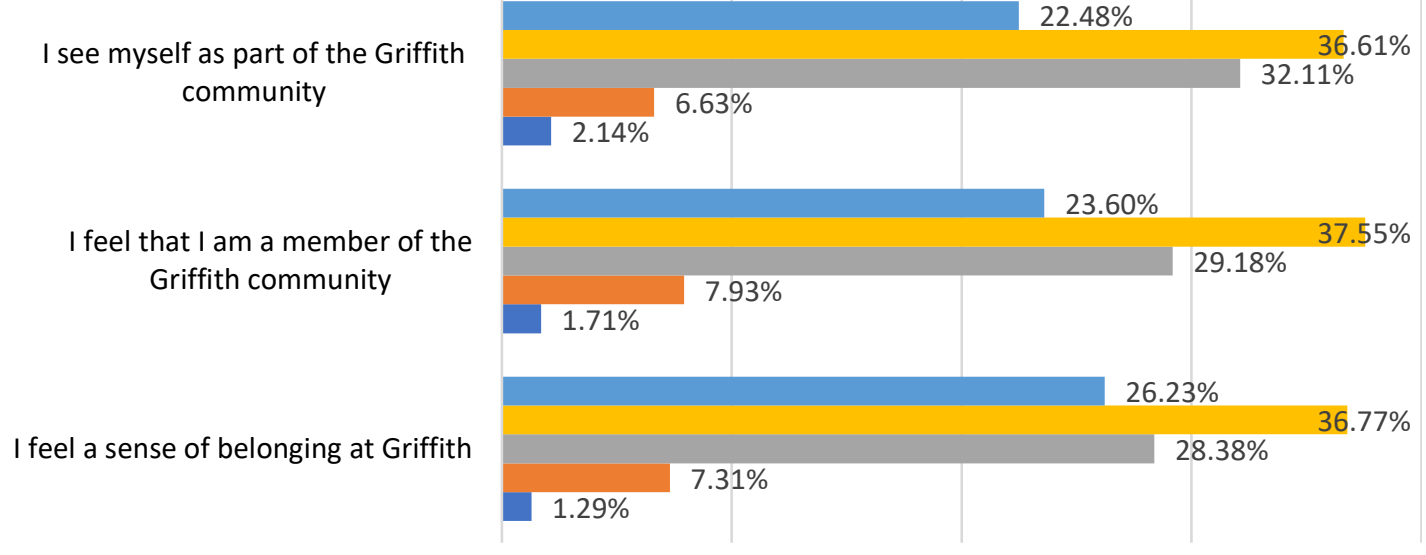

$\square$ Strongly agree $\square$ Agree $\square$ Neither agree nor disagree $\square$ Disagree $\square$ Strongly disagree

\footnotetext{
${ }^{1}$ These categories were: Emails/Phone Calls/Information, Friends, Mentors, myGriffith, No, Not Yet, Orientation Sessions, Other, School/Group Staff and Activities, Student Societies, Support Services, Want on Campus, Yes.
} 


\section{Census Week Survey}

Surveys were sent to commencing students in week 5 of trimester with the same questions as those in the orientation week survey to assess students' ongoing sense of belonging and the long-term effect of the PECS-based orientation sessions. This survey round had 102 responses and indicated a small decline in students' sense of belonging. While the sense of belonging statements in the orientation week surveys received average overall scores of 3.7 out of 5 , the week 5 surveys returned average ratings of 3.5 .

\section{Figure 3}

Likert Responses to Week 5 Survey (\%)

I see myself as part of the Griffith community

I feel that I am a member of the Griffith community

I feel a sense of belonging at Griffith

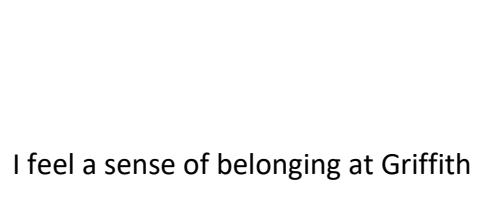

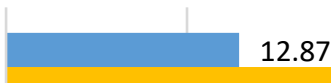
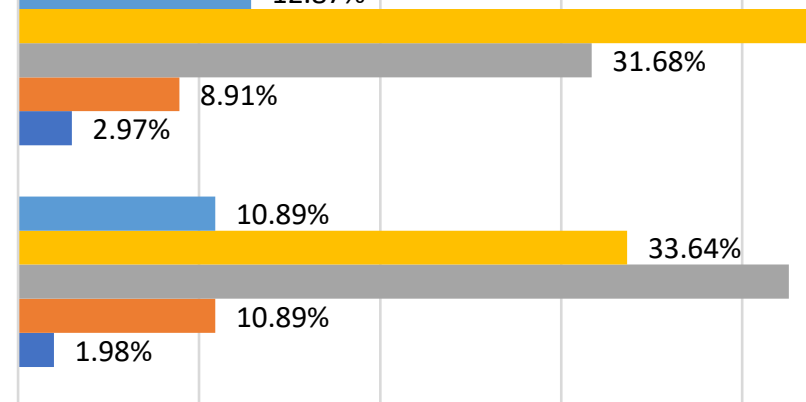

$10.89 \%$
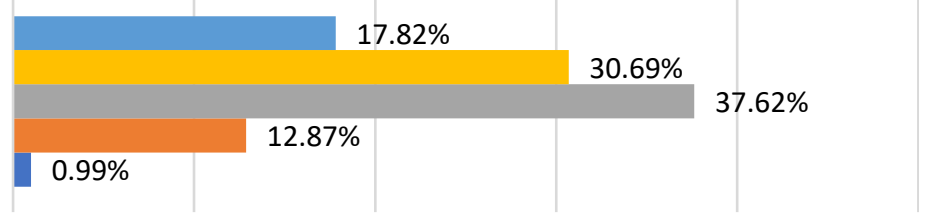

- Strongly agree $\quad$ Agree $\square$ Neither agree nor disagree $\square$ Disagree $\quad$ Strongly disagree

There was a similar change in the proportions of sense of belonging statement responses. Of the 303 statement responses, 151 $(50 \%)$ indicated students' strong or moderate sense of belonging to Griffith, $113(37 \%)$ indicated neither agreement nor disagreement with the sense of belonging propositions, and 39 (12\%) registered disagreement.

Of 102 responses, the PECS-based orientation sessions were identified as having helped students to feel that they belonged at Griffith on 26 occasions (23\%). This means that, despite this survey being distributed over five weeks after the orientation sessions, they were still mentioned more frequently than any other response. The next most mentioned factors reported to have helped students develop a sense of belonging were mentors ( $\mathrm{n} .=15)$ and school/group staff and activities (n.=14). Eight students responded "no", and 19 students highlighted campus closures as the reason they could not form a sense of belonging.

\section{Discussion}

This study aimed to understand three issues: the extent to which orientation events designed using the PECS framework support enjoyable student experiences; the extent to which orientation events designed using the PECS framework support the development of commencing students' sense of belonging, and; the extent to which such a sense of belonging lasted through the academic trimester. Results show that despite the limitations of campus closures and a lockdown during the time of orientation, the PECS-based Griffith Welcome Sessions registered high student satisfaction ratings. Students' reported sense of belonging at Griffith was also strong and widespread during orientation week. Student free answer responses indicated that the PECS model worked in creating enjoyable orientation experiences, connecting students, providing them with essential information, and facilitating the growth of a sense of belonging. 
It is difficult to ascertain the long-term influence of the Griffith Welcome Sessions on students' sense of belonging. It is clear from the week 5 survey results that students' sense of disconnection from the university grew after weeks of being unable to attend campus or interact in person with their teachers, peers, or mentors. Despite these challenges, almost a quarter of survey respondents still identified the Griffith Welcome Sessions as having helped to develop their sense of belonging at university. Thus, it may be the case that the extended orientation strategy lessened the disconnecting effects of campus closures. More research must be conducted about the long-term efficacy of PECS-based orientation events, but this initial study indicates that the PECs orientation event framework does foster students' sense of connection with their new university.

\section{Conclusion}

The PECS framework was designed based on university transition research and published best practice reports. The framework offers a simple means for university staff to ensure their orientation event is focused on developing students' sense of belonging. The data analysed in this article indicates that while it may be difficult to ascertain its long-term influence, the PECS framework appears to facilitate the development of new students' sense of belonging at the most crucial stage of their university experience - the start. More research is necessary to better understand the effect of the PECS framework as well as how different uses of the model might influence commencing student cohorts. What the data collected and analysed in this study indicates is that the PECS model, as applied by the STAM team in the Griffith Welcome Sessions, offered commencing students consistent and enjoyable experiences that positively influenced their sense of belonging at Griffith. 


\section{References}

Ahn, M. Y. (2017). Sense of belonging as an indicator for social capital: A mixed methods analysis of students' sense of belonging to university [Doctoral dissertation, Bangor University]. https://research.bangor.ac.uk/portal/en/theses/sense-ofbelonging-as-an-indicator-for-social-capital-a-mixed-methods-analysis-of-students-sense-of-belonging-touniversity(c54c267b-f939-4463-9763-a58d12fcc398).html

Ahn, M. Y., \& Davis, H. H. (2020). Four domains of students' sense of belonging to university. Studies in Higher Education, 45(3), 622-634. https://doi.org/10.1080/03075079.2018.1564902

Beil, C., Reisen, C. A., Zea, M. C., \& Caplan, R. C. (1999). A longitudinal study of the effects of academic and social integration and commitment on retention. NASPA Journal, 37(1), 376. https://doi.org/10.2202/1949-6605.1094

Bollen, K. A., \& Hoyle, R. H. (1990). Perceived cohesion: A conceptual and empirical examination. Social Forces, 69(2), 479-504. https://doi.org/10.1093/sf/69.2.479

Brunelle-Joiner, K. M. (2000). Effects of an extended orientation program on personal resiliency and adjustment to college as it relates to academic performance and retention. Humanities and Social Sciences, 60(2-A): 354. https://doi.org/10.18297/etd/105

Cabras, C., \& Mondo, M. (2018). Future orientation as a mediator between career adaptability and life satisfaction in university students. Journal of Career Development, 45(6), 597-609. https://doi.org/10.1177/0894845317727616

Chiu, M. M., Chow, B. W.-Y., McBride, C., \& Mol, S. T. (2016). Students' sense of belonging at school in 41 countries: Cross-cultural variability. Journal of Cross-Cultural Psychology, 47(2), 175-196. https://doi.org/10.1177/0022022115617031

Cohen, R. D. (2019). Freshman seminar: A new orientation. Routledge.

Collins, N., \& Dodsworth, E. (2011). Reaching first-year students during orientation week. Partnership: The Canadian Journal of Library and Information Practice and Research, 6(2). https://doi.org/10.21083/partnership.v6i2.1473

Davis, G. M., Hanzsek-Brill, M. B., Petzold, M. C., \& Robinson, D. H. (2019). Students' sense of belonging: The development of a predictive retention model. Journal of the Scholarship of Teaching and Learning, 19(1), 117-127. https://doi.org/10.14434/josotl.v19i1.26787

Dilekmen, M. (2007). Orientation program and adaptation of university students. Psychological Reports, 101(3_suppl), 1141-1144. https://doi.org/10.2466\%2Fpr0.101.4.1141-1144

Fink, A. (2002). How to ask survey questions. SAGE.

Gijn-Grosvenor, E. L., \& Huisman, P. (2020). A sense of belonging among Australian university students. Higher Education Research \& Development, 39(2), 376-389. https://doi.org/10.1080/07294360.2019.1666256

Hodgkinson, S. P., \& Innes, J. M. (2001). The attitudinal influence of career orientation in 1st-year university students: Environmental attitudes as a function of degree choice. The Journal of Environmental Education, 32(3), 37-40. https://doi.org/10.1080/00958960109599144

Kift, S. (2009). Articulating a transition pedagogy to scaffold and to enhance the first year student learning experience in Australian higher education: Final report for ALTC senior fellowship program. Australian Learning and Teaching Council. http://transitionpedagogy.com/

Krause, K.-L., Hartley, R., James, R., \& McInnis, C.(2005). The first year experience in Australian universities: Findings from a decade of national studies. Centre for the Study of Higher Education. https://www.voced.edu.au/content/ngv\%3A11049

Kuh, G. D. (1991). The role of admissions and orientation in creating appropriate expectations for college life. College and University, 66(2), 75-82.

Larmar, S., \& Ingamells, A. (2010). Enhancing the first-year university experience: Linking university orientation and engagement strategies to student connectivity and capability. Research in Comparative and International Education, 5(2), 210-223. https://doi.org/10.2304/rcie.2010.5.2.210

Miles, S. (2019). Centering the needs of first-generation college students: The "FYRST" extended orientation program. [Master's thesis, West Chester University] https://digitalcommons.wcupa.edu/all theses/60

Morrow, J. A., \& Ackermann, M. E. (2012). Intention to persist and retention of first-year students: The importance of motivation and sense of belonging. College Student Journal, 46(3), 483-491.

O’Brien, M., Llamas, M., \& Stevens, E. (2012). Lessons learned from four years of peer mentoring in a tiered group program within education. Journal of the Australian \& New Zealand Student Services Association, 40(1), 7-15.

O'Keeffe, P. (2013). A sense of belonging: Improving student retention. College Student Journal, 47(4), 605-613.

Pascarella, E. T., \& Terenzini, P. T. (1980). Predicting freshman persistence and voluntary dropout decisions from a theoretical model. Journal of Higher Education, 51(1), 60-75. https://doi.org/10.1007/BF00979592

Pittaway, S., \& Moss, T. (2006, July 12-14). Contextualising student engagement: Orientation and beyond in teacher education. 9th Pacific Rim First Year in Higher Education Conference [Conference presentation], Gold Coast Australia.

Singer, W. (2003). The role of the campus visit and the summer orientation program in the modification of student expectations about college. Journal of College Orientation, Transition, and Retention, 10(2). 
Thomas, L. (2013). What works? Facilitating an effective transition into higher education. Widening Participation and Lifelong Learning, 14(1), 4-24.

Thongsawat, S., Davidson-Shivers, G., \& Chatphoomiphong, B. (2019). Designing an interactive student orientation to build social connectedness. Journal of Educational Multimedia and Hypermedia, 28(1), 99-112.

Tinto, V. (1993). Leaving college: Rethinking the causes and cures of student attrition. University of Chicago Press.

Tokoya, T. (2019). The predictability of selected orientation program factors on the academic success and retention of international students [Doctoral dissertation, Texas Southern University]. http://search.proquest.com/docview/2352101160/abstract/889D7580E3E7439APQ/1

Webb, M., \& Spiese, C. (2018, June). Extended orientation for undergraduate pathways students. North America Academic Conference Marshall University, United States

https://mds.marshall.edu/into_conference/into_academic_conference_2018/wednesday_june_20/3/

Please cite this article as:

Cooper, R. (2021). PECS: An evidence-based orientation event framework for enhancing students' sense of belonging. Student Success, 12(2), 51-60. https://doi.org/10.5204/ssj.1906

This article has been peer reviewed and accepted for publication in Student Success. Please see the Editorial Policies under the 'About' section of the Journal website for further information.

Student Success: A journal exploring the experiences of students in tertiary education

(c) (i) Except where otherwise noted, content in this journal is licensed under a Creative Commons Attribution 4.0 International Licence. As an open access journal, articles are free to use with proper attribution. ISSN: 2205-0795 